\title{
Anchor Dragging Analysis of Rock-Berm Using Smoothed Particle Hydrodynamics Method
}

\author{
Jinho Woo, Dongha Kim, and Won-Bae Na \\ Department of Ocean Engineering, Pukyong National University, Busan 608-737, Republic of Korea \\ Correspondence should be addressed to Won-Bae Na; arizcat@gmail.com
}

Received 7 August 2014; Accepted 19 October 2014

Academic Editor: Ting-Hua Yi

Copyright (C) 2015 Jinho Woo et al. This is an open access article distributed under the Creative Commons Attribution License, which permits unrestricted use, distribution, and reproduction in any medium, provided the original work is properly cited.

\begin{abstract}
This study presents dynamic responses of rock-berm structural system under anchor dragging and accordingly provides the characteristics of the stresses and displacements obtained. For the purpose, first, a rock-berm was modeled by the SPH (smoothed particle hydrodynamics) method and piecewise Drucker-Prager material model by facilitating the associated software packageANSYS-AUTODYN. Second, 2-ton stockless anchor was modeled as a rigid body and eventually dragging external force was obtained. Then, the dragging velocity ( 1 and $2 \mathrm{~m} / \mathrm{s}$ ) was considered as a parameter to investigate the effect of its variation on the responses. Finally, the dragging tensile forces of the anchor cable were obtained and compared according to the dragging velocities. It is shown that the four-layer rock-berm gives the safety margin to the submarine power cable according to the unaffected gauge points near the cable. This safety is accomplished by the four layers (related to rock-berm height) and the number of rock particles at each layer (related to rock-berm widths).
\end{abstract}

\section{Introduction}

Submarine power cables have been used to connect dots and accordingly transmit electric power from the main land to an island. Recent developments in ocean renewable energies make the conventional energy flows in another direction such as offshore wind farms to the main land. This innovation requires the frequent use of submarine power cables; hence, their safety assurance methods have been developed.

Among the methods, rock-berms have been used in relatively deep waters because of their easy installation and inexpensive cost. A recent study showed that rock-berm height and rock size are important parameters against an accidental load-anchor collision [1]. Along with anchor collision, anchor dragging is also important for the protecting structures [2]. Yoon and $\mathrm{Na}$ [2] investigated the dynamic responses of a flexible concrete mattress through field experiments. However, no one has investigated the behaviors of rock-berms under anchor dragging so far.

This fact extends to numerical studies because the conventional Lagrange method is not applicable in the modeling of rocks [3] but applicable in tunnel-type protective structures $[4,5]$. Accordingly, it is demanded to develop a numerical procedure, to evaluate the dynamic behaviors of a rock-berm under anchor dragging, and to acquire the safety assessment of submarine power cables, which are installed under rockberms.

This study presents dynamic responses of rock-berm behaviors under anchor dragging and accordingly provides the characteristics of the stresses and displacements obtained. For the purpose, first, a rock-berm was modeled by the SPH (smoothed particle hydrodynamics) method and piecewise Drucker-Prager material model by facilitating the associated software package-ANSYS-AUTODYN [6]. Second, 2-ton stockless anchor was modeled as a rigid body and eventually dragging external force was obtained. Then, the dragging velocity ( 1 and $2 \mathrm{~m} / \mathrm{s}$ ) was considered as a parameter to investigate the effect of its variation on the responses. Finally, the dragging tensile forces of the anchor cable were obtained and compared according to the dragging velocities.

It should be noted here that this study is limited to investigating the dynamic responses of the target structure under anchor dragging. Other issues such as monitoring of the transient responses [7], multistage structural damage diagnosis [8], and more detailed signal process [9] should be considered in further research activities. 


\section{Materials and Methods}

The SPH method was initially developed by Gingold and Monaghan [10] and Lucy [11] for astrophysical problems. It has been used in many research fields such as astrophysics, ballistics, volcanology, and oceanography because it is a mesh-free Lagrange method and resolution can easily be adjusted according to variables such as the density. Most initial problems are fluid-related by dividing the fluid into a set of discrete elements (particles). Libersky and Petschek [12] extended the SPH to solid mechanics. The main advantage of SPH in solids is the possibility of dealing with the larger local distortion than grid-based methods; hence, it has been exploited in many applications in solid mechanics such as metal forming, collision, crack growth, fracture, and fragmentation. The detailed description of the SPH method and associated references can be found in the literature [13]. Here, we introduce the brief concept of the SPH method.

The SPH method uses kernel approximation, which is based on randomly distributed interpolation points with no assumptions about which points are neighbors, to calculate spatial derivatives and particle density using Kernel estimation [14]. The particle density can be expressed using kernel approximation as follows:

$$
\rho^{I}=\sum_{J=1}^{N} m^{J} W^{I J}\left(x^{I}-x^{J}, h\right)
$$

where $\rho^{I}$ is the density of $I$ th particle, $m^{J}$ is the mass of $J$ th particle, and $W^{I J}\left(x^{I}-x^{J}, h\right)$ is the weight function according to particle size $h . x^{I}$ and $x^{J}$ are $x$-coordinates of $I$ th and $J$ th particle. In the SPH method, the particle density can be obtained as mass of neighbor particle multiplied by weight function. Figure 1 shows a schematic of the weight function in SPH method. In the study, the Kernel B-spline is used as the weight function. The basic form of weight function is as follows:

$$
w(u)= \begin{cases}1-6 u^{2}+6 u^{3}, & 0 \leq u \leq \frac{1}{2} \\ 2(1-u)^{3}, & \frac{1}{2}<u \leq 1 \\ 0, & u>1,\end{cases}
$$

where $u$ is a parametric variable defined by $u=\left|x^{I}-x^{J}\right| /(2 h)$.

Two contact conditions were considered, as shown in Figure 2. First, the interface between rock and other materials (basement and anchor) is based on the contact algorithms used in Lagrange-oriented finite element codes. Second, the interface between the stones (particle to particle contact) is based on the meshless approach [15]. If other material intersects the circle of a particle, then contact is assumed to be occurred. When contact occurs, the restoring force is applied along the normal to the surface. In the particle to particle contact, restoring forces are applied between particles.

Rock-berm is a typical example on which the $\mathrm{SPH}$ method is applicable because rock-berm is a structure constructed by stacking rocks to protect lifelines (e.g., submarine power cables and pipelines) and to build breakwaters.

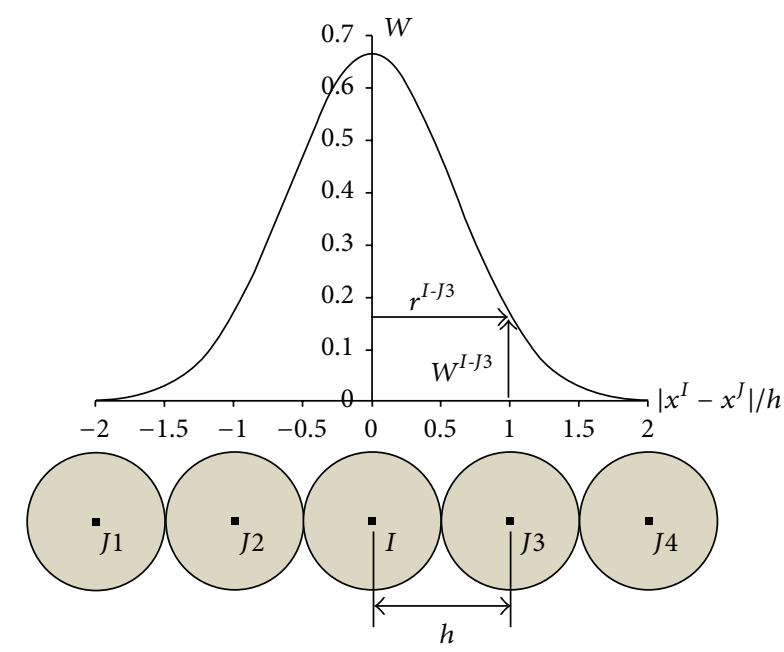

FIGURE 1: The schematic of the weight function.

TABLE 1: Material properties of seabed (sand).

\begin{tabular}{lccc}
\hline & Density $\left(\mathrm{kg} / \mathrm{m}^{3}\right)$ & $\begin{array}{c}\text { Young's } \\
\text { modulus }(\mathrm{MPa})\end{array}$ & Poisson ratio \\
\hline Elastic sand & 2200 & 81 & 0.3 \\
\hline
\end{tabular}

Figure 3 shows a rock-berm consisting of rock particles (the upper layers) modeled by the SPH method and lower seabed layers modeled by 8 -node solid elements. The linear elastic material properties were used for modeling of the seabed layers, as shown in Table 1. The piecewise Drucker-Prager material model was used for modeling of the rock layers because the material model is frequently used for the discrete materials such as concrete, rocks, and soils $[16,17]$. In the rock material model, we used the material properties of Table 2, which is proposed by Chen et al. [18] and the associated pressure-yield stress curve, shown in Figure 4.

The rock-berm size was determined according to Cberm, which was proposed by the Korean Electric Power Corporation [19]. The bottom width is $7 \mathrm{~m}$, the top width is $2 \mathrm{~m}$, the height is $1.2 \mathrm{~m}$, and the slope angle is $25.64^{\circ}$ as shown in Figure 3 . The diameters of the rocks typically range from 100 to $300 \mathrm{~mm}$ in the practice; hence, the upper bound $300 \mathrm{~mm}$ was used in the study. In reality, the rock-berm extends to the $z$ and $-z$ directions for the continuous layout; hence, two symmetry planes (the boundary planes A and B in Figure 3) were assumed and constrained in the horizontal $(z$ and $-z)$ directions. In addition, the seabed bottom plane was constrained in the vertical direction.

The target anchor (2-ton stockless) is one of anchors frequently used in commercial and other vessels in the Korean waters. It was modeled according to the Korea Standard [20] and modeled by 4-node shell elements for the dragging analysis, as shown in Figure 5. Moreover, the anchor is assumed to be a rigid body because the density $\left(7200 \mathrm{~kg} / \mathrm{m}^{3}\right)$ and Young's modulus (170 GPa) are much larger than those of the rocks and seabed. Table 3 shows the anchor considered and its representative dimensions [20]. As shown in Figure 3, 


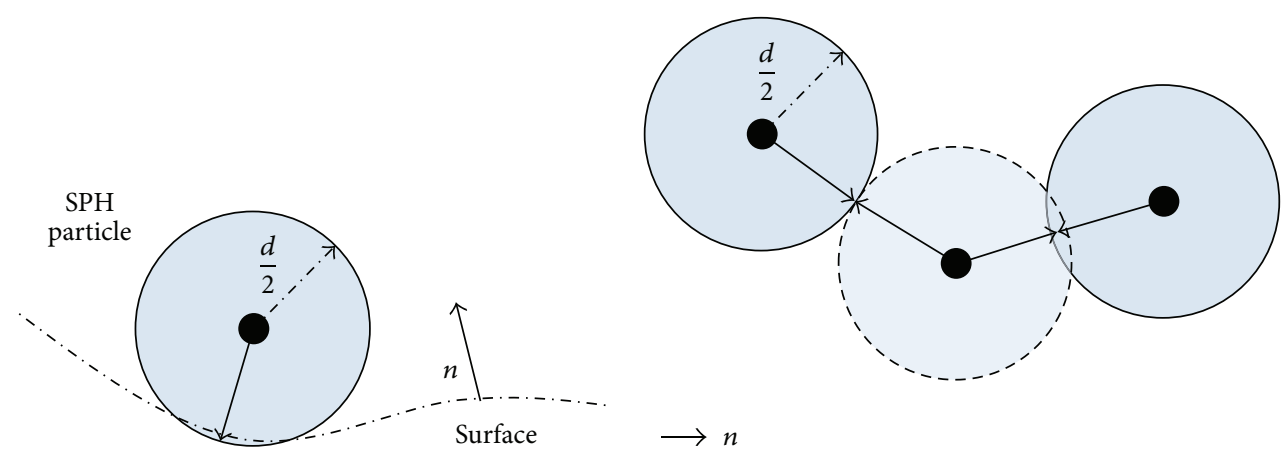

(a) Particle to surface contact

(b) Particle to particle contact

FIgURE 2: Contact conditions: (a) particles to surface contact and (b) particle to particle contact.

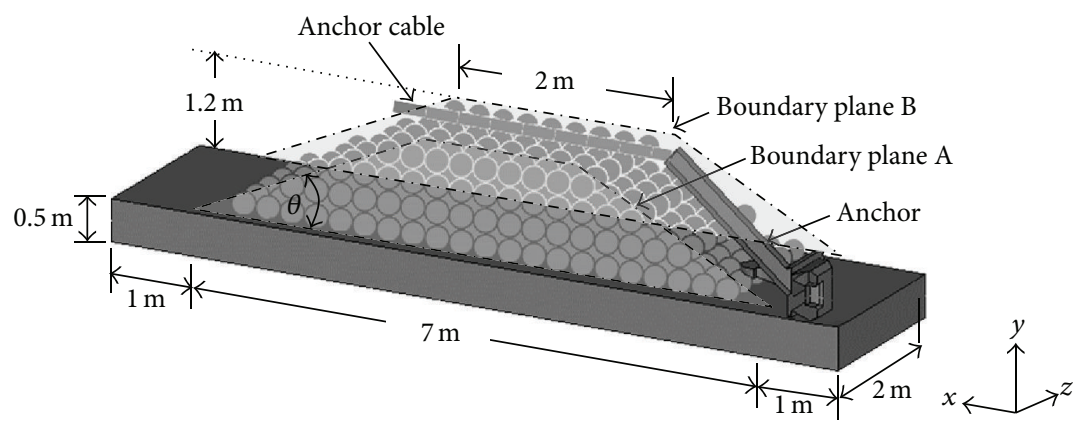

Figure 3: Dimension of rock-berm and its boundary planes (A and B).

TABLE 2: Material properties of rock for Drucker-Prager model.

\begin{tabular}{lc}
\hline Parameter & Value \\
\hline Density $\left(\mathrm{kg} / \mathrm{m}^{3}\right)$ & 2750 \\
Bulk modulus $(\mathrm{GPa})$ & 35.7 \\
Pressure 1 $(\mathrm{MPa})$ & -30 \\
Pressure 2 $(\mathrm{MPa})$ & -26.7 \\
Pressure 3 $(\mathrm{MPa})$ & 200 \\
Pressure 4 $(\mathrm{MPa})$ & 1000 \\
Pressure 5 $(\mathrm{MPa})$ & 2500 \\
Shear modulus $(\mathrm{GPa})$ & 17.44 \\
Hydro tensile limit $(\mathrm{MPa})$ & 30 \\
Yield stress 1 $(\mathrm{MPa})$ & 0 \\
Yield stress 2 $(\mathrm{MPa})$ & 40 \\
Yield stress 3 $(\mathrm{MPa})$ & 450 \\
Yield stress 4 $(\mathrm{MPa})$ & 1430 \\
Yield stress 5 $(\mathrm{MPa})$ & 2530 \\
\hline
\end{tabular}

TABLE 3: Specifications of target anchors.

\begin{tabular}{lccc}
\hline Anchor type & $\begin{array}{c}\text { Width of anchor } \\
(\mathrm{mm})\end{array}$ & $\begin{array}{c}\text { Height of shank } \\
(\mathrm{mm})\end{array}$ & $\begin{array}{c}\text { Height of } \\
\text { anchor }(\mathrm{mm})\end{array}$ \\
\hline 2-ton stockless & 1040 & 2404 & 1340 \\
\hline
\end{tabular}

the 2-ton stockless anchor was guided (attached) by the anchor cable, which is modeled by line (link) elements

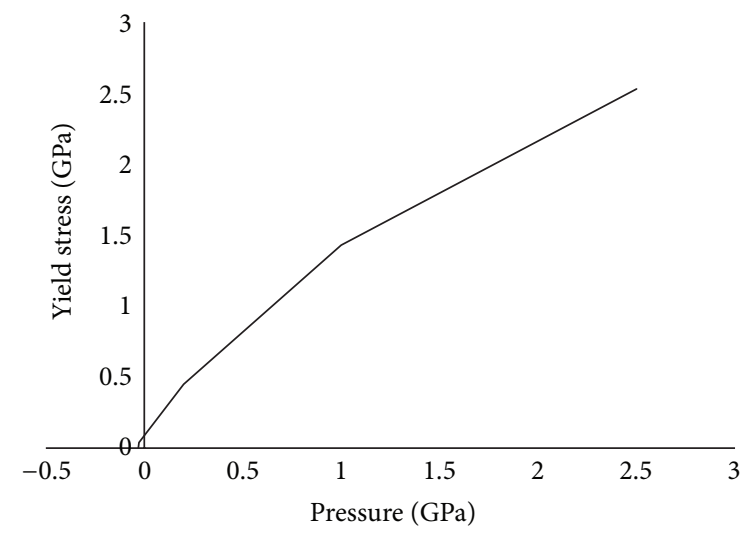

FIgure 4: Pressure-yield stress curve for piecewise Drucker-Prager model.

(density: $7850 \mathrm{~kg} / \mathrm{m}^{3}$ and Young's modulus: $210 \mathrm{GPa}$ ). The cable is always under tension; hence, the conventional cable element which can resist the tension only is not necessary. Besides, the geometrical nonlinearity of the anchor cable was not considered because of the external force is tension-only. The dragging location was assumed to be the bottom of the 2nd layer (Layer B) at the boundary plane A, as shown in Figure 6. Two dragging scenarios were made by considering two dragging velocities ( 1 and $2 \mathrm{~m} / \mathrm{s}$ ). 


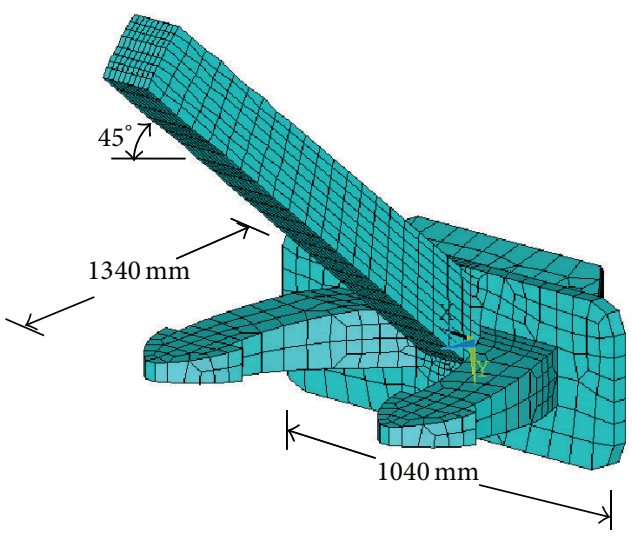

FIGURE 5: 2-ton stockless anchor model.

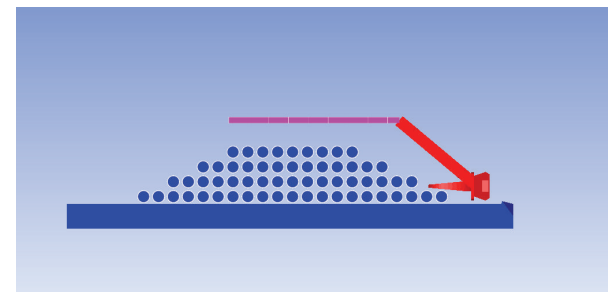

Figure 6: Cross-section at the symmetric boundary plane A.

To get the dynamic responses, 11 gauge points are specified as shown in Figure 7. In the figure, each layer has its own name, for example, Layer A, Layer B, Layer C, and Layer D; hence, the gauge points are named to indicate the layers. For example, Al denotes the first gauge point locating at Layer A. The coordinates of the gauge points are given in Table 4 . It should be noted here that the location of submarine power cables is just below A1 because the position of the number " 1 " is the center of the rock-berm ( $y$-axis).

\section{Results and Discussions}

The von-Mises stress (equivalent stress) is often used in determining whether a material will yield when subjected to a complex loading condition. Figure 8 shows the von-Mises stresses at the gauge points (A1-D2) when dragging velocity is $1 \mathrm{~m} / \mathrm{s}$ (first scenario). Initially, the stresses at A3 and B3 are distinct because the anchor dragging starts at the right side between Layer A and Layer B. The stresses at B3 are bigger than those at A3 due to the dragging direction (left or $+x$ direction) and the bottom boundary condition. After approximately $1.5 \mathrm{sec}$, the stresses at $\mathrm{C} 2$ and D2 exceed the stresses at A3, which indicates that the anchor is moving up. Then, the stresses at $\mathrm{C} 1$ and $\mathrm{D} 1$ exceed the stresses at $\mathrm{A} 3$ after around $2.0 \mathrm{sec}$, which denotes that the anchor reaches at the top layer (Layer D). It should be emphasized that the stresses at $\mathrm{A} 1$ are almost zero; hence, the submarine power does not tends to experience stresses. Over the period, the maximum von-Mises stress is approximately $4.3 \mathrm{kPa}$, which occurs at $\mathrm{C} 2$ and D2, as shown in Table 5.

Figure 9 shows the horizontal displacements (UX). Initially, the front particles (A3, A4, and B3) move to the left

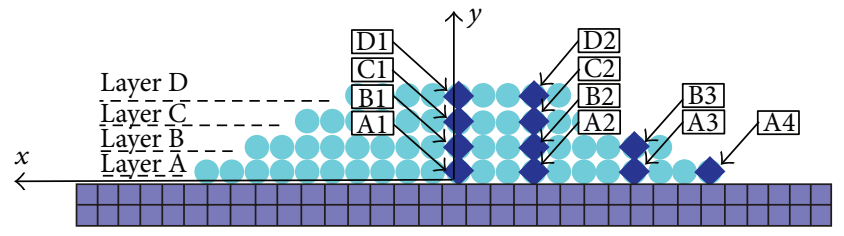

FIGURE 7: Gauge points of rock-berm.

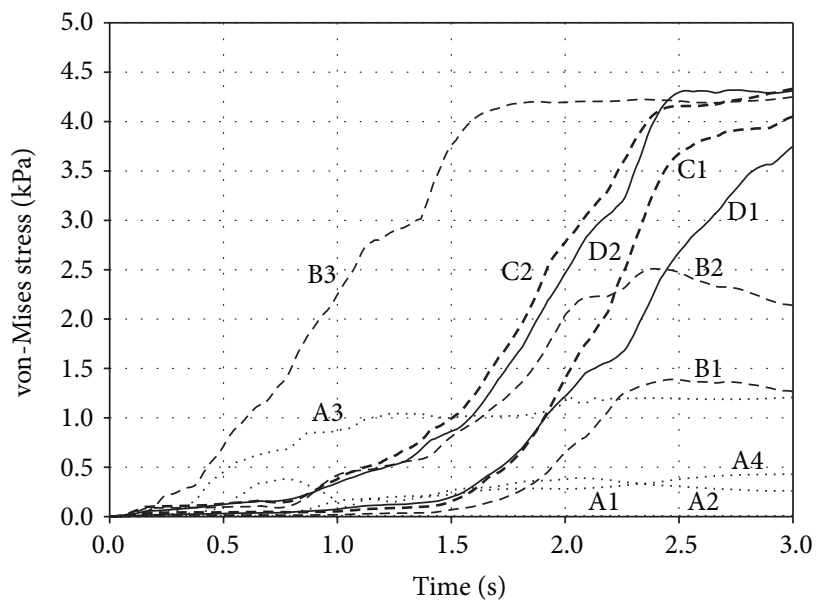

FIGURE 8: von-Mises stresses at gauge points when dragging velocity is $1 \mathrm{~m} / \mathrm{s}$.

TABLE 4: Coordinates of gauge points.

\begin{tabular}{lccc}
\hline $\begin{array}{l}\text { Gauge } \\
\text { points }\end{array}$ & $x$-coordinate $(\mathrm{m})$ & $y$-coordinate $(\mathrm{m})$ & $z$-coordinate $(\mathrm{m})$ \\
\hline A1 & -0.05 & 0.15 & 0.15 \\
A2 & -0.95 & 0.15 & 0.15 \\
A3 & -2.15 & 0.15 & 0.15 \\
A4 & -3.05 & 0.15 & 0.15 \\
B1 & -0.05 & 0.45 & 0.15 \\
B2 & -0.95 & 0.45 & 0.15 \\
B3 & -2.15 & 0.45 & 0.15 \\
C1 & -0.05 & 0.75 & 0.15 \\
C2 & -0.95 & 0.75 & 0.15 \\
D1 & -0.05 & 1.05 & 0.15 \\
D2 & -0.95 & 1.05 & 0.15 \\
\hline
\end{tabular}

( $+x$ direction) according to the anchor dragging and then followed by C2 and D2 and accordingly D1. The horizontal displacements at the gauge points $\mathrm{A} 1, \mathrm{~A} 2$, and $\mathrm{B} 1$ are almost zero, which indicate that the particles do not receive main effect from the dragging movement. The maximum UX are about $855 \mathrm{~mm}$ at D1. Figure 10 shows the vertical displacements (UY). Initially, the front particles (A3 and B3) move upward ( $+y$ direction) and then followed by $\mathrm{Cl}$ and $\mathrm{D} 1$. An interesting factor is that the D2 experiences the downward movement ( $-y$ direction) after around $2.0 \mathrm{sec}$. This means the corresponding particle is disintegrated. It is also shown that the vertical displacements at $\mathrm{A} 1, \mathrm{~A} 2, \mathrm{~A} 4$, and $\mathrm{B} 1$ are almost 


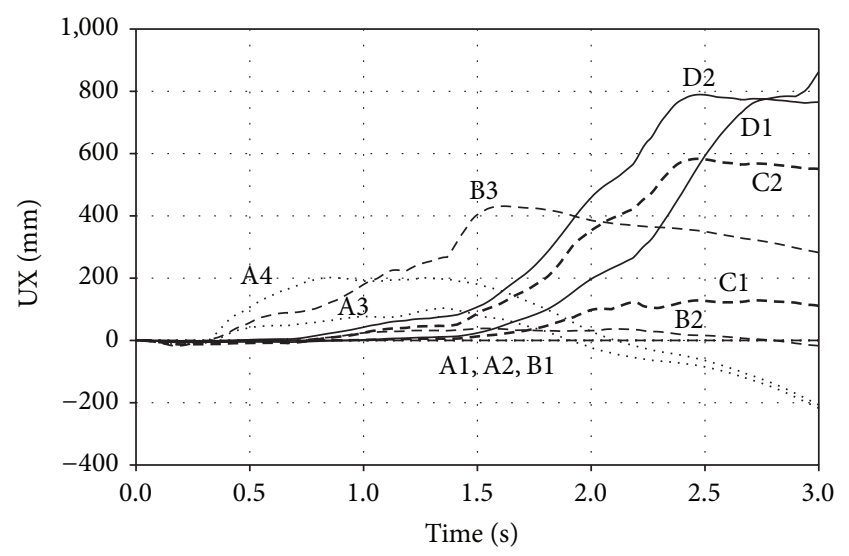

FIGURE 9: Horizontal displacements (UX) at gauge points when dragging velocity is $1 \mathrm{~m} / \mathrm{s}$.

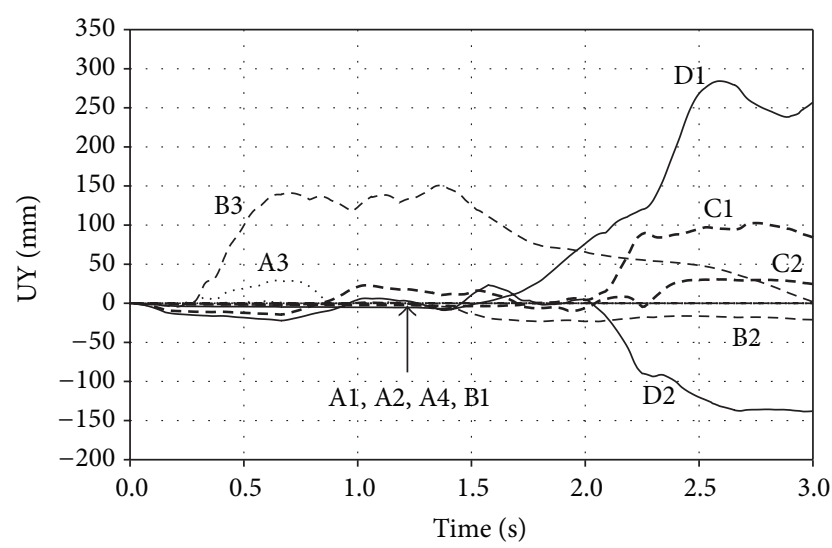

Figure 10: Vertical displacements (UY) at gauge points when dragging velocity is $1 \mathrm{~m} / \mathrm{s}$.

TABle 5: Maximum von-Mises stresses at gauge points when dragging velocity is $1 \mathrm{~m} / \mathrm{s}$.

\begin{tabular}{lc}
\hline Gauge point & Max. von-Mises stress $(\mathrm{kPa})$ \\
\hline A1 & 0.0003 \\
A2 & 0.3930 \\
A3 & 1.2220 \\
A4 & 0.4300 \\
B1 & 1.3890 \\
B2 & 2.5090 \\
B3 & 4.2500 \\
C1 & 4.0480 \\
C2 & 4.3310 \\
D1 & 3.7490 \\
D2 & 4.3190 \\
\hline
\end{tabular}

zero over the time interval, standing for less effective zone of the anchor dragging. The maximum UY is approximately $283 \mathrm{~mm}$ at D1.

To pinpoint the particle movement, Figure 11 shows the movement sequence according to time. From the figure,

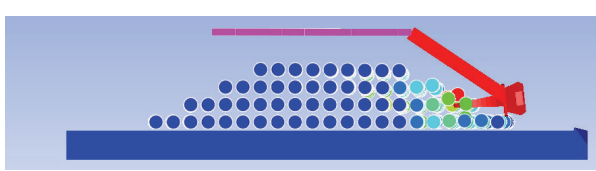

(a) $0.5 \mathrm{sec}$

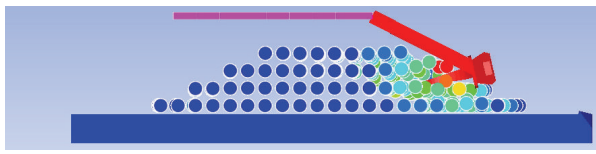

(b) $1.0 \mathrm{sec}$

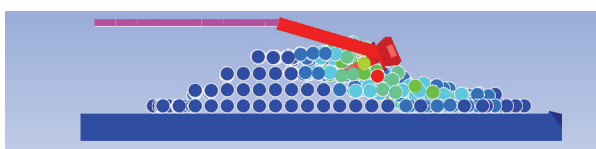

(c) $2.0 \mathrm{sec}$

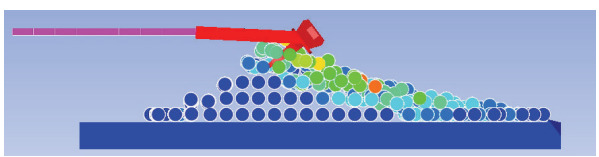

(d) $3.0 \mathrm{sec}$

FIGURE 11: von-Mises stress according to time when dragging velocity is $1 \mathrm{~m} / \mathrm{s}$.

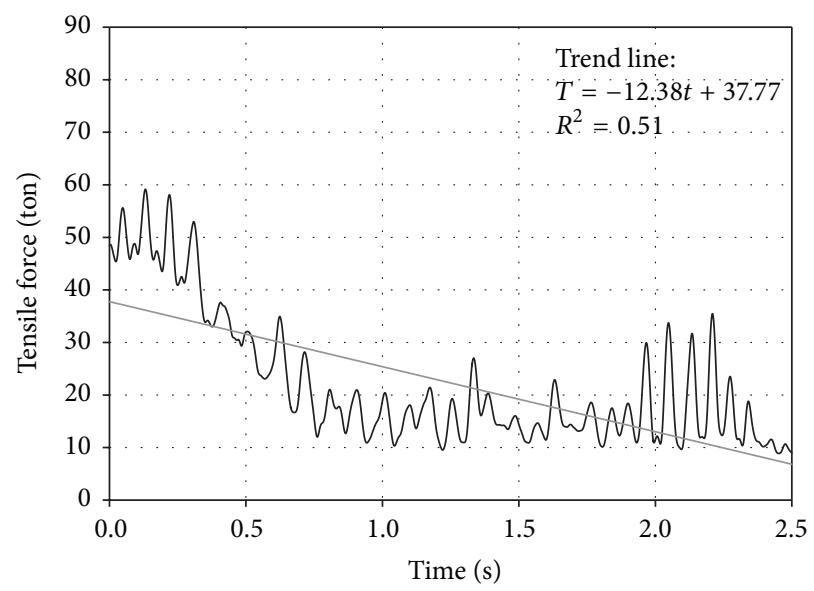

FIGURE 12: Tensile force of cable when dragging velocity is $1 \mathrm{~m} / \mathrm{s}$.

it is clearly observed that the stockless anchor penetrated, dragged, and disintegrated the rocks as time goes. However, it does not cause a significant response at A1, which locates at the top of the submarine power cable. Thus, the dragging scenario does not threaten the safety of the power cable. Figure 12 shows the tensile force of the anchor cable. The initial tensile force is 50 ton, then the force tends to decrease to 10 to 25 ton when the anchor penetrated the rocks (between 0.7 and $2.0 \mathrm{sec}$ ), and then the force increases to 10 to 35 ton when the anchor gives a deeper penetration into the rocks (after $2 \mathrm{sec}$ ). This late increase of the tensile force is caused by the upper layer rocks, which do not roll down from the rockberm as shown in Figure 11. 


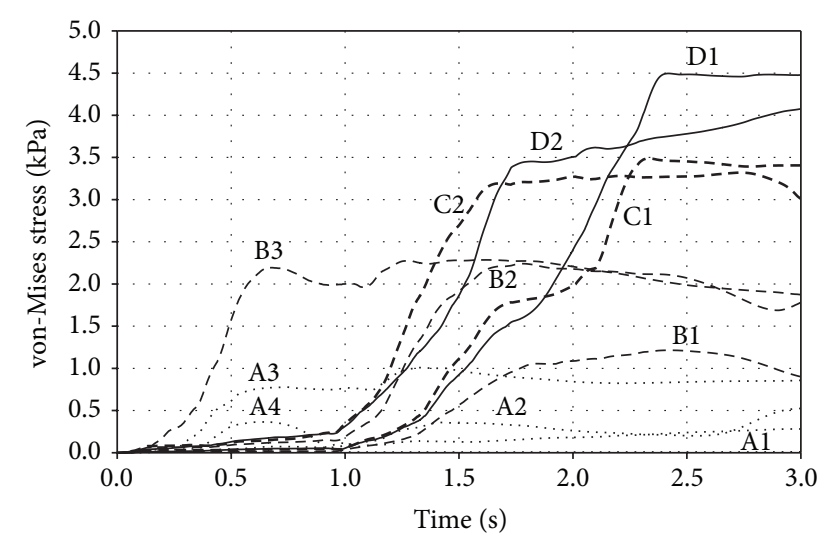

FIGURE 13: von-Mises stresses at gauge points when dragging velocity is $2 \mathrm{~m} / \mathrm{s}$.

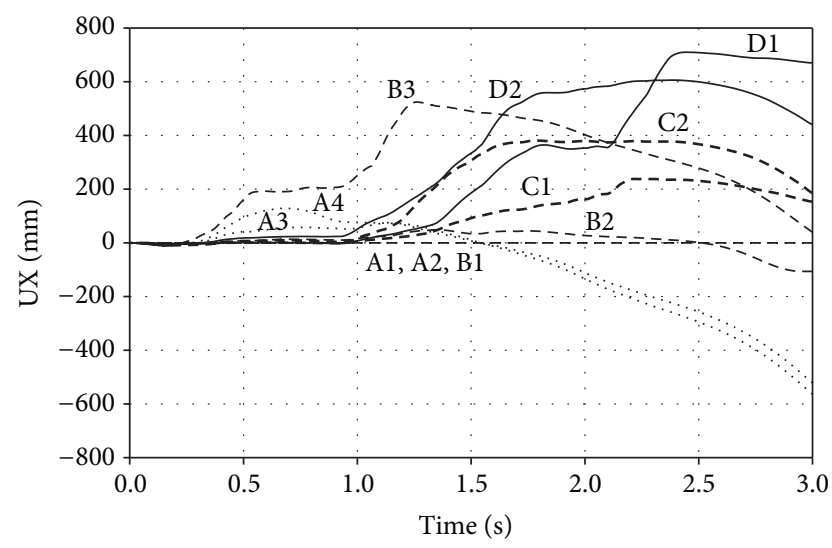

FIGURE 14: Horizontal displacements (UX) at gauge points when dragging velocity is $2 \mathrm{~m} / \mathrm{s}$.

Figure 13 shows the von-Mises stresses at the gauge points (A1-D2) when dragging velocity is $2 \mathrm{~m} / \mathrm{s}$. Initially, the stresses at $\mathrm{A} 3, \mathrm{~A} 4$, and $\mathrm{B} 3$ are distinct because the anchor dragging starts at the right side between Layer A and Layer B. The stresses at B3 are bigger than those at A3 and $\mathrm{A} 4$ due to the dragging direction ( $+x$ direction) and the bottom boundary condition. After approximately $1.3 \mathrm{sec}$, the stresses at $\mathrm{C} 2$ and D2 exceed the stresses at A3, which indicates that the anchor is moving up. Then, the stresses at $\mathrm{C} 1$ and $\mathrm{D} 1$ exceed the stresses at $\mathrm{A} 3$ after around $1.5 \mathrm{sec}$, which denotes that the anchor reaches at the top layer (Layer D). It should be emphasized that the stresses at $\mathrm{Al}$ are almost zero; hence, the submarine power does not tend to experience stresses. Over the period, the maximum von-Mises stress is approximately $4.5 \mathrm{kPa}$, which occurs at $\mathrm{D} 1$, as shown in Table 6. In comparison with the first scenario, the second scenario shows the similar characteristics but little earlier occurrence than those of $1 \mathrm{~m} / \mathrm{s}$ because of the faster dragging velocity $(2 \mathrm{~m} / \mathrm{s})$.

Figure 14 shows the horizontal displacements (UX) in the case of $2 \mathrm{~m} / \mathrm{s}$ of dragging velocity. Initially, the front particles (A3, A4, and B3) move to the left ( $+x$ direction) according to the anchor dragging and then followed by $\mathrm{C} 2$

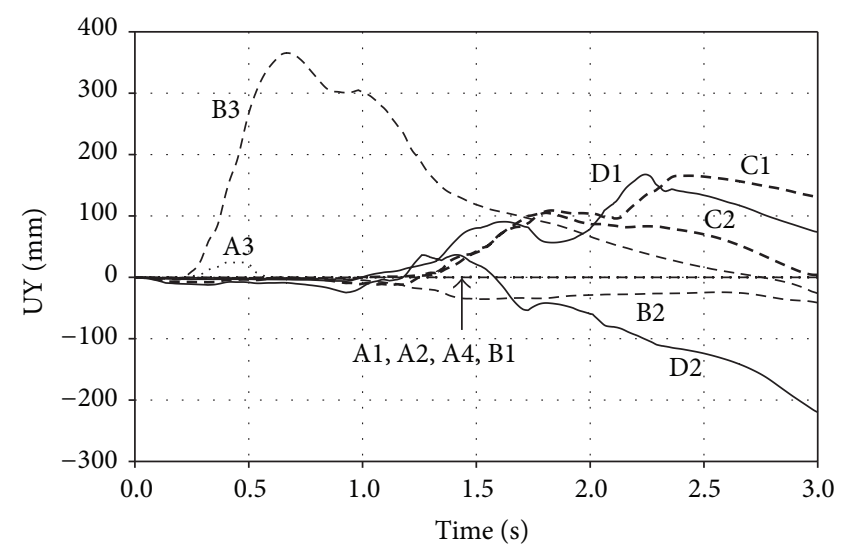

FIGURE 15: Vertical displacements (UY) at gauge points when dragging velocity is $2 \mathrm{~m} / \mathrm{s}$.

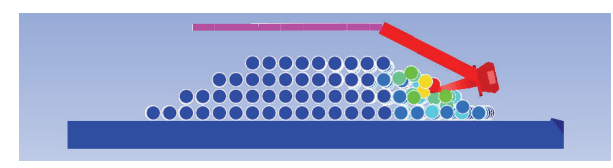

(a) $0.5 \mathrm{sec}$

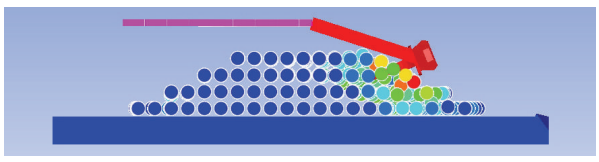

(b) $1.0 \mathrm{sec}$

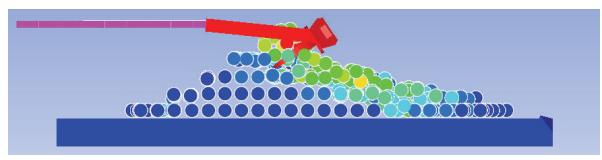

(c) $2.0 \mathrm{sec}$

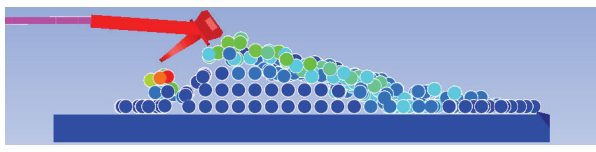

(d) $3.0 \mathrm{sec}$

FIGURE 16: von-Mises stress according to time when dragging velocity is $2 \mathrm{~m} / \mathrm{s}$.

and D2 and accordingly D1. The horizontal displacements at the gauge points $\mathrm{A} 1, \mathrm{~A} 2$, and $\mathrm{B} 1$ are almost zero, which indicate that the particles do not receive main effect from the dragging movement. The maximum UX are about $710 \mathrm{~mm}$ at D1. Figure 15 shows the vertical displacements (UY) in the second scenario. Initially, the front particles (A3 and B3) move upward ( $+y$ direction) and then followed by $\mathrm{C} 1$ and D1. An interesting factor is that the D2 experiences the downward movement ( $-y$ direction) after around $1.7 \mathrm{sec}$. This means the corresponding particle is totally disintegrated. It is also shown that the vertical displacements at A1, A2, A4, and $\mathrm{B} 1$ are almost zero over the time interval, standing for less effective zone of the anchor dragging. The maximum UY is approximately $365 \mathrm{~mm}$ at $\mathrm{B} 3$, unlike the first scenario 


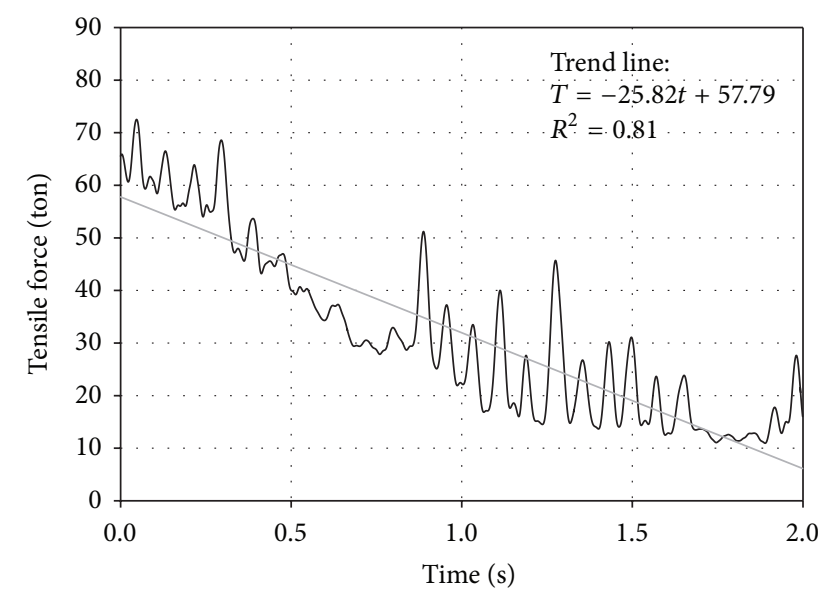

Figure 17: Tensile force of cable when dragging velocity is $2 \mathrm{~m} / \mathrm{s}$.

TABle 6: Maximum von-Mises stresses at gauge points when dragging velocity is $2 \mathrm{~m} / \mathrm{s}$.

\begin{tabular}{lc}
\hline Gauge point & Max. von-Mises stress $(\mathrm{kPa})$ \\
\hline $\mathrm{A} 1$ & 0.0028 \\
$\mathrm{~A} 2$ & 0.5250 \\
$\mathrm{~A} 3$ & 1.0080 \\
$\mathrm{~A} 4$ & 0.3650 \\
$\mathrm{~B} 1$ & 1.2140 \\
$\mathrm{~B} 2$ & 2.2410 \\
$\mathrm{~B} 3$ & 2.2850 \\
$\mathrm{C} 1$ & 3.4890 \\
$\mathrm{C} 2$ & 3.3200 \\
$\mathrm{D} 1$ & 4.4960 \\
$\mathrm{D} 2$ & 4.0750 \\
\hline
\end{tabular}

showing that the maximum UY occurs at D1. This indicates that higher dragging velocity causes larger vertical movement at the initial period. In comparison with the first scenario, the second scenario shows the similar characteristics but little earlier movement than those of $1 \mathrm{~m} / \mathrm{s}$ because of the faster dragging velocity $(2 \mathrm{~m} / \mathrm{s})$.

To pinpoint the particle movement, Figure 16 shows the movement sequence according to time. From the figure, it is clearly observed that the stockless anchor penetrated, dragged, and disintegrated the rocks as time goes. However, it does not cause a significant response at A1, which locates at the top of the submarine power cable. Thus, the dragging scenario does not threaten the safety of the power cable. In comparison with the first scenario, as shown in Figures 8 and 13, the higher dragging velocity causes much faster anchor movement, and accordingly the stockless anchor is already separated from the rock-berm at $3.0 \mathrm{sec}$. Thus, more disintegration or disturbance of the rocks happens in the second scenario. Figure 17 shows the tensile force of the anchor cable. The initial tensile force is 65 ton, and then the force tends to decrease as time goes. The tensile force of the second scenario has a more distinct decreasing pattern than that of the first scenario (see the trend lines and their characters of Figures 12 and 17). This can be explained by the early escape of the anchor from the rock-berm in the second scenario.

\section{Conclusion}

By facilitating the SPH method, it is shown that the global behavior of the rock-berm is not much sensitive to the dragging velocity. This indicates that the gauge points give similar responses although the responding moments are little different according to the velocity variation. However, the faster dragging force $(2 \mathrm{~m} / \mathrm{s})$ gives more rapid disintegration of the rock-berm, and accordingly the late responses are relatively distinguishable. Moreover, considering the tensile force of the anchor cable, the higher velocity $(2 \mathrm{~m} / \mathrm{s})$ gives a more distinct decreasing pattern of the tensile force than that of the lower velocity $(1 \mathrm{~m} / \mathrm{s})$ as time goes because of the early escape of the anchor from the rock-berm. The fourlayer rock-berm gives the safety margin to the submarine power cable according to the unaffected gauge points near the cable. This safety is accomplished by the four layers (rockberm height) and the number of rock particles at each layer (related to rock-berm widths and slope angle). Therefore, the dimensions (height $=1.2 \mathrm{~m}$, lower width $=7 \mathrm{~m}$, upper width $2 \mathrm{~m}$, and slope angle $=25.64^{\circ}$ ) provide the safety of submarine power cables under the anchor dragging scenarios.

\section{Conflict of Interests}

The authors declare that there is no conflict of interests regarding the publication of this paper.

\section{Acknowledgment}

This research was a part of the project titled "Development on the Guidelines of Safety Assessment for Submarine Cable Protection Facilities in Shallow Water" funded by the Ministry of Land, Transport and Maritime Affairs, Korea (KIMT2012-20120018).

\section{References}

[1] J. Woo and W. B. Na, "Safety assessment of rock-berms under anchor collision for protecting submarine power cables," Ocean Engineering. In press.

[2] H.-S. Yoon and W.-B. Na, "Safety assessment of submarine power cable protectors by anchor dragging field tests," Ocean Engineering, vol. 65, pp. 1-9, 2013.

[3] J. Woo, D. Kim, H.-S. Yoon, and W.-B. Na, "Characterizing Korean general artificial reefs by drag coefficients," Ocean Engineering, vol. 82, pp. 105-114, 2014.

[4] J. Woo and W. B. Na, "Analyses of the maximum response of cylinders-connected protectors under anchor colliding and dragging," Journal of Ocean Engineering and Technology, vol. 24, pp. 81-87, 2010 (Korean).

[5] J. Woo, W. B. Na, and H. T. Kim, "Numerical simulation of archtype submarine cable protector under anchor collision," Journal of Ocean Engineering and Technology, vol. 23, pp. 96-103, 2009 (Korean). 
[6] ANSYS, AUTODYN User Manual Version 12.0, ANSYS, Canonsburg, Pa, USA, 2009.

[7] T. H. Yi, H. N. Li, and M. Gu, "A new method for optimal selection of sensor location on a high-rise building using simplified finite element model," Structural Engineering and Mechanics, vol. 37, no. 6, pp. 671-684, 2011.

[8] T.-H. Yi, H.-N. Li, and H.-M. Sun, "Multi-stage structural damage diagnosis method based on "energy-damage" theory," Smart Structures and Systems, vol. 12, no. 3-4, pp. 345-361, 2013.

[9] H. Li, T. Yi, M. Gu, and L. Huo, "Evaluation of earthquakeinduced structural damages by wavelet transform," Progress in Natural Science, vol. 19, no. 4, pp. 461-470, 2009.

[10] R. A. Gingold and J. J. Monaghan, "Smoothed particle hydrodynamics: theory and application to non-spherical stars," Monthly Notices of the Royal Astronomical Society, vol. 181, pp. 375-389, 1977.

[11] L. B. Lucy, "A numerical approach to the testing of the fission hypothesis," The Astronomical Journal, vol. 82, pp. 1013-1024, 1977.

[12] L. D. Libersky and A. G. Petschek, "Smooth particle hydrodynamics with strength of materials," in Advances in the FreeLagrange Method Including Contributions on Adaptive Gridding and the Smooth Particle Hydrodynamics Method, vol. 395 of Lecture Notes in Physics, pp. 248-257, Springer, Berlin, Germany, 1991.

[13] J. Lin, H. Naceur, D. Coutellier, and A. Laksimi, "Efficient meshless SPH method for the numerical modeling of thick shell structures undergoing large deformations," International Journal of Non-Linear Mechanics, vol. 65, pp. 1-13, 2014.

[14] C. J. Hayhurst, R. A. Clegg, I. H. Livingstone, and N. J. Francis, "The application of SPH techniques in AUTODYN-2D to ballistic impact problems," in Proceeding of the 16th International Symposium on Ballistics, San Francisco, Calif, USA, 1996.

[15] S. Seo and O. Min, "Axisymmetric SPH simulation of elastoplastic contact in the low velocity impact," Computer Physics Communications, vol. 175, no. 9, pp. 583-603, 2006.

[16] W. K. Liu, S. Jun, S. Li, J. Adee, and T. Belytschko, "Reproducing kernel particle methods for structural dynamics," International Journal for Numerical Methods in Engineering, vol. 38, no. 10, pp. 1655-1679, 1995.

[17] X. H. Zhu and Y. J. Jia, "3D mechanical modeling of soil orthogonal cutting under a single reamer cutter based on DruckerPrager criterion," Tunnelling and Underground Space Technology, vol. 41, no. 1, pp. 255-262, 2014.

[18] S. G. Chen, J. Zhao, A. Makurati, and C. Madshus, "Discrete element modeling of an explosion test in granite," in Proceedings of GeoEng2000: An International Conference on Geotechnical \& Geological Engineering, 19-24 November 2000, Melbourne Exhibition and Convention Centre, Melbourne, Australia, pp. 1474-1481, 2000.

[19] KEPCO, Field Test Report for Installation of Rock Berm in the Shallow Water of Jindo-Jeju Island HVDC Interconnection Project, Korea Electric Power Corporation, 2010 (Korean).

[20] KS V 3311, Anchors, Korean Standards Association, 2012. 

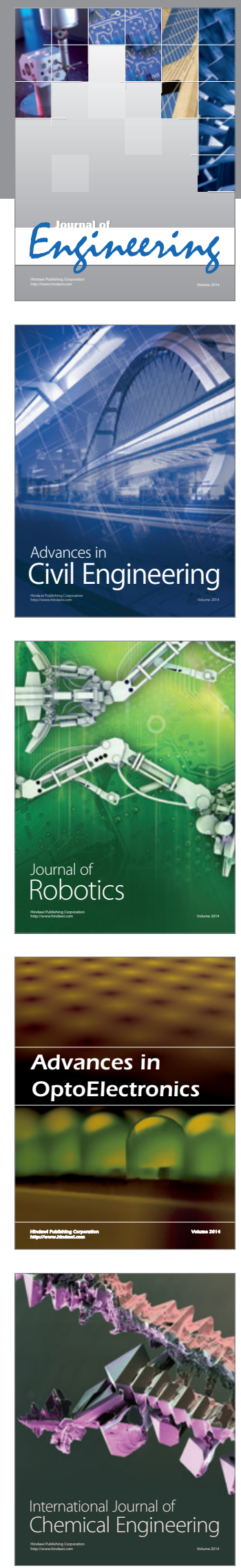

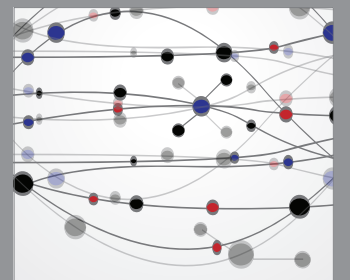

The Scientific World Journal
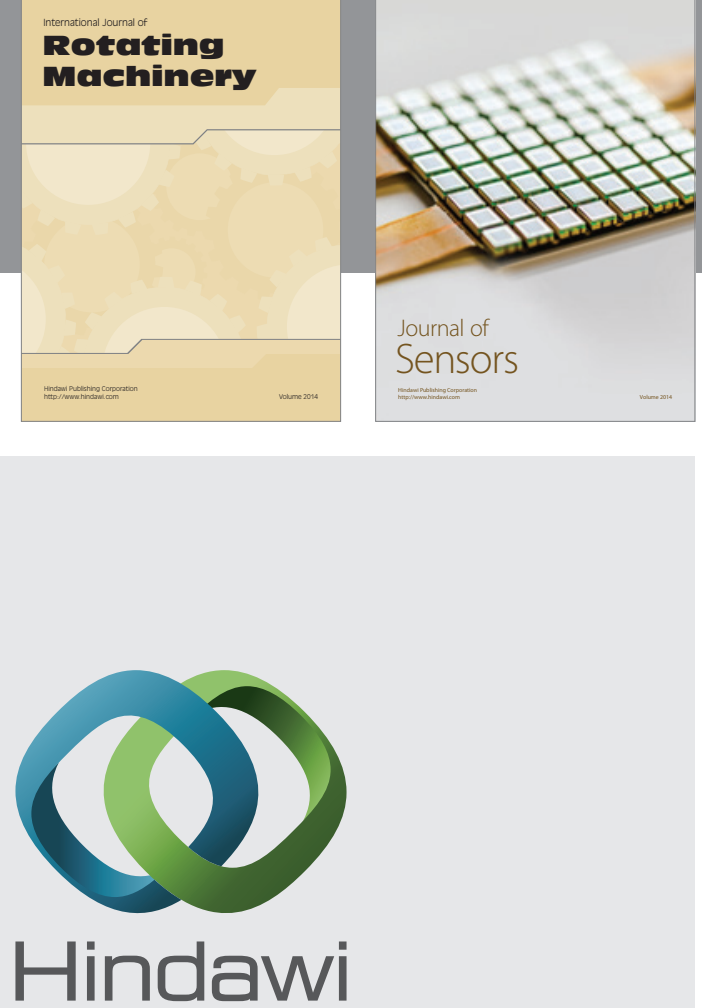

Submit your manuscripts at http://www.hindawi.com
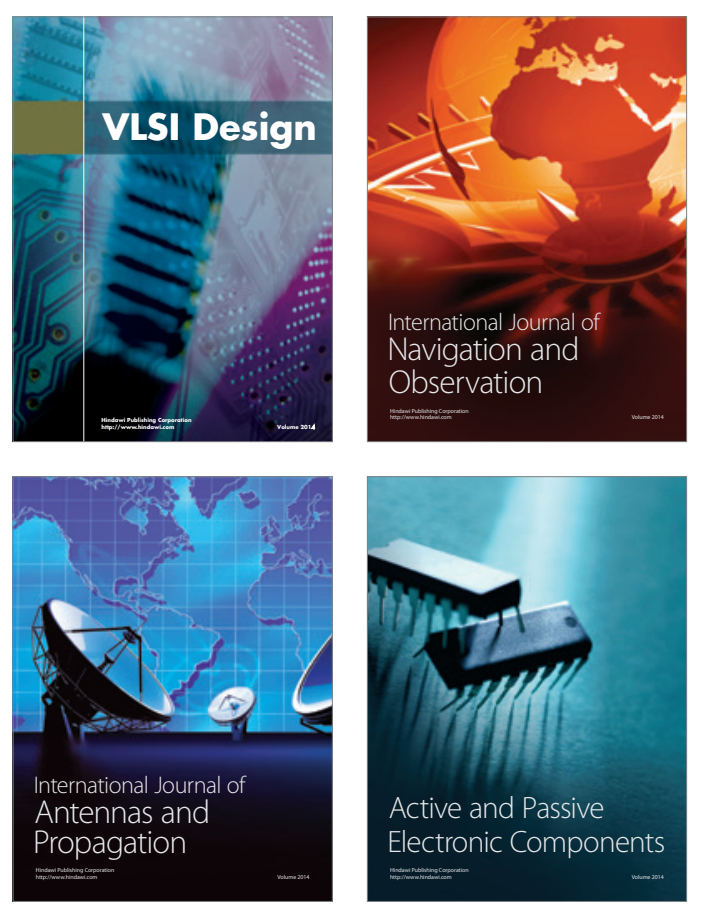
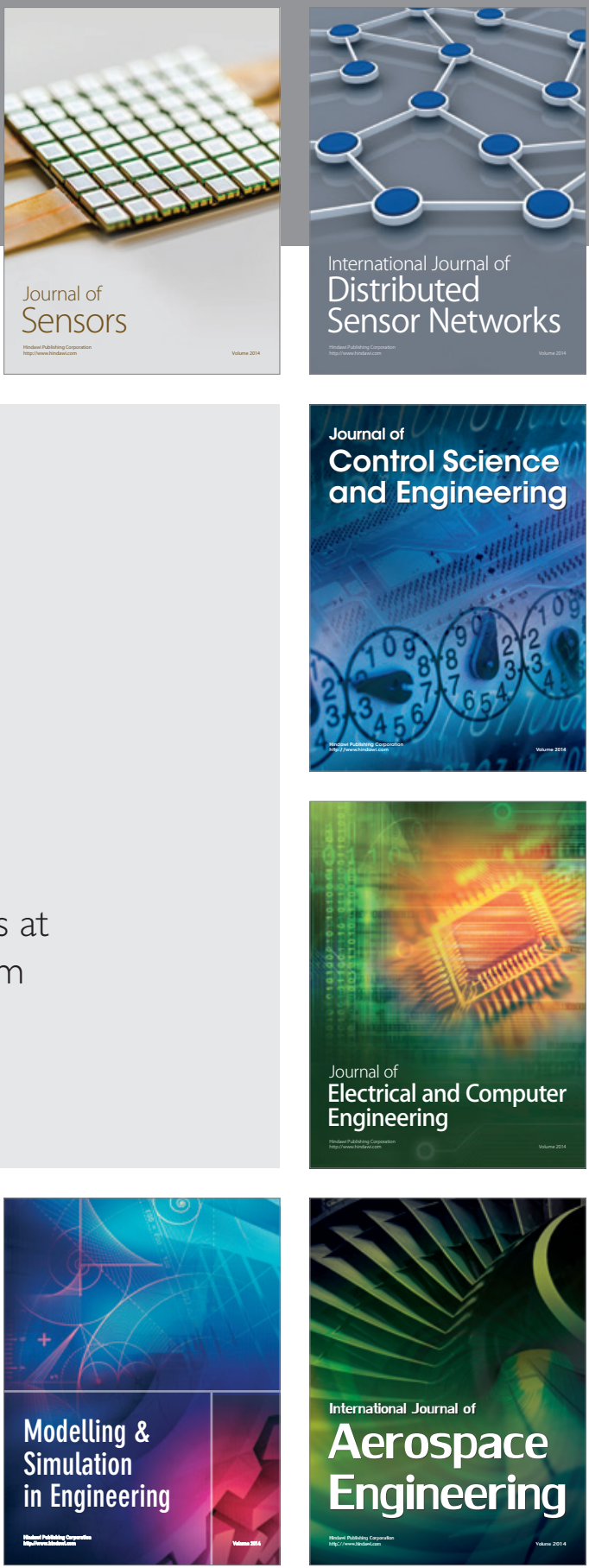

Journal of

Control Science

and Engineering
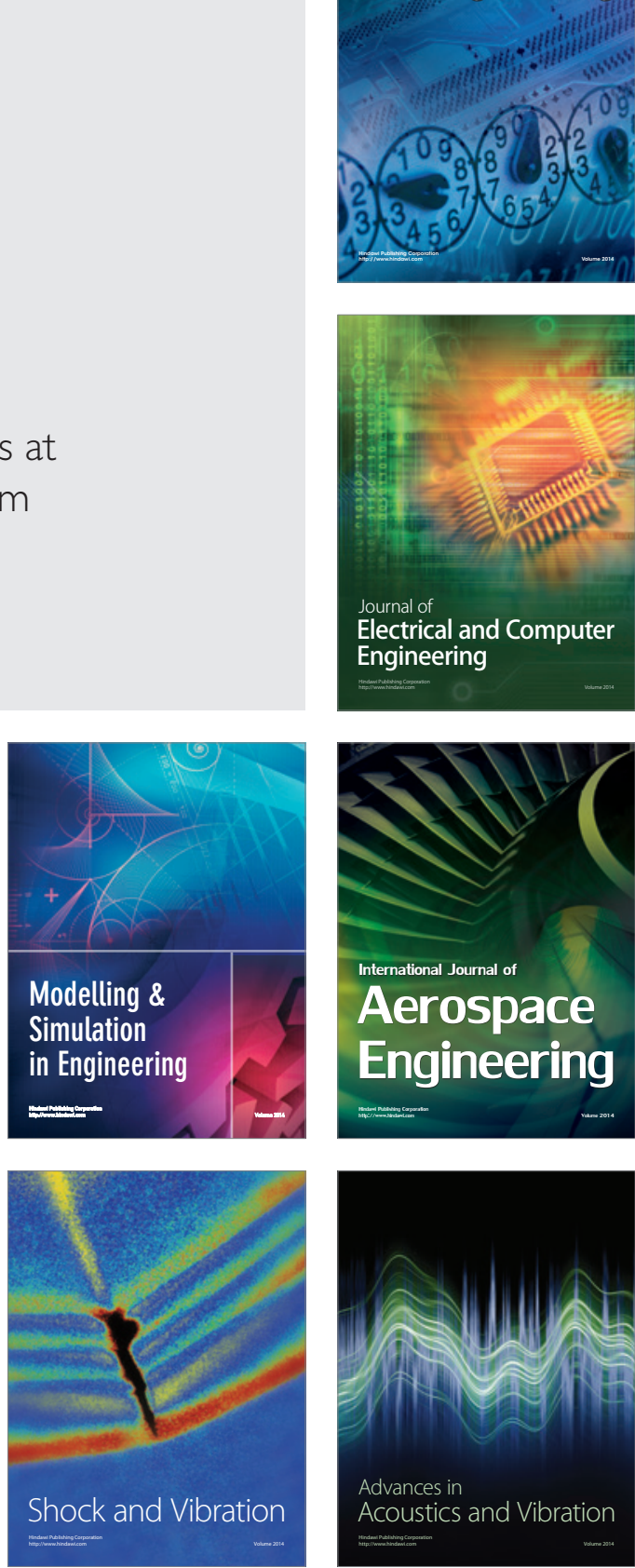